\title{
The inner workings of my mind
}

They say a man with no dreams,

Is like a film with no theme.

Void of meaning, lacklustre and dry,

Like a seagull that can't fly.

I stagger through life,

With nothing but strife.

Feelings of sorrow and pain,

Fall relentlessly like a Monsoon rain.

No more powerful evil can I find,

Than to be imprisoned within my own mind.

The rare sober moment with feeling so awkward,

How many more drinks until I am slaughtered.

\section{Nicky Collard}

Millview Hospital, Hove, UK

Correspondence to Dr James Fallon, Promenade Ward, Millview Hospital, Nevill Avenue, Hove BN3 7HZ, UK; James.fallon@sussexpartnership.nhs.uk

Acknowledgements Dr James Fallon for submitting this poem to Medical Humanities on behalf of Nicky Collard.

Contributors The poem that is submitted was produced wholly by NC, a patient of the Mental Health Homeless Team in Brighton. NC provided consent for submission to this journal. JF submitted this on behalf of NC.

Competing interests None.

Provenance and peer review Not commissioned; externally peer reviewed.

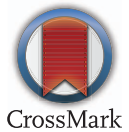

To cite Collard N. Med Humanit 2014;41:e2.

Med Humanit 2014;41:e2. doi:10.1136/medhum-2014-010619 